OPEN ACCESS

Edited by:

Mitsuhiro Kawata,

Kyoto Prefectural University of Medicine, Japan

Reviewed by: Adhil Bhagwandin,

University of Cape Town, South Africa Miguel Ángel García-Cabezas,

Universidad Autónoma de Madrid y

Consejo Superior de Investigaciones Cientificas, Spain

*Correspondence: Francisco Aboitiz faboitiz@puc.cl

Received: 30 April 2021 Accepted: 03 June 2021 Published: 23 June 2021

Citation: Aboitiz F and Montiel JF (2021) The Enigmatic Reissner's Fiber and the Origin of Chordates.

Front. Neuroanat. 15:703835. doi: 10.3389/fnana.2021.703835

\section{The Enigmatic Reissner's Fiber and the Origin of Chordates}

\author{
Francisco Aboitiz ${ }^{1,2 *}$ and Juan F. Montie/ ${ }^{3}$ \\ ${ }^{1}$ Departamento de Psiquiatría, Escuela de Medicina, Pontificia Universidad Católica de Chile, Santiago, Chile, ${ }^{2}$ Centro \\ Interdisciplinario de Neurociencias, Pontificia Universidad Católica de Chile, Santiago, Chile, ${ }^{3}$ Centro de Investigación \\ Biomédica, Facultad de Medicina, Universidad Diego Portales, Santiago, Chile
}

Reissner's fiber (RF) is a secreted filament that floats in the neural canal of chordates. Since its discovery in 1860, there has been no agreement on its primary function, and its strong conservation across chordate species has remained a mystery for comparative neuroanatomists. Several findings, including the chemical composition and the phylogenetic history of RF, clinical observations associating RF with the development of the neural canal, and more recent studies suggesting that RF is needed to develop a straight vertebral column, may shed light on the functions of this structure across chordates. In this article, we will briefly review the evidence mentioned above to suggest a role of RF in the origin of fundamental innovations of the chordate body plan, especially the elongation of the neural tube and maintenance of the body axis. We will also mention the relevance of RF for medical conditions like hydrocephalus, scoliosis of the vertebral spine and possibly regeneration of the spinal cord.

Keywords: Reissner's fiber, chordates, vertebrates, notochord, neural tube, swimming behavior, cerebrospinal fluid

\section{INTRODUCTION}

The phylum Chordata, including lancelets (cephalochordates -Amphioxus), sea squirts (urochordates), and vertebrates, is partly characterized by the presence of a segmented musculature flanking a fibrous notochord that defines a semi-rigid anteroposterior axis, and a muscular postanal tail used for swimming. Another typical feature of chordates is that the central nervous system is shaped as a hollow neural tube that runs from head to tail, filled with cerebrospinal fluid (CSF) that circulates along the neural canal (NCa) (Figure 1; Wicht and Lacalli, 2005; Aboitiz and Montiel, 2007; Glover and Fritzsch, 2009; Striedter and Northcutt, 2020). The anatomical and behavioral innovations acquired by this group provided the blueprint from which vertebrates emerged and colonized the earth. Nonetheless, the evolutionary origin of chordates themselves remains as one of the great unsolved questions of evolutionary biology (Satoh, 2008; Holland et al., 2015). In this context, the notochord is considered by many a cardinal feature of chordates, being involved in the development of some of the principal characters of this phylum, especially the tailbud and the neural tube (Henrique et al., 2015; Sasai et al., 2021).

In this article, we propose the additional participation of Reissner's fiber (RF), another highly conserved but much less conspicuous feature of chordates, which probably collaborated with the notochord in the origin of this animal group. RF is a structure secreted to the NCa that arises in early development of most chordates. Despite its phylogenetic preservation and early embryonic origins, the functions of RF have been a matter of discussion for more than a century. Many authors have suggested a role of this fiber in the chemical regulation of the CSF and in the maintenance of 
the NCa, which together with its phylogenetic conservatism may hint to a participation in the early evolution of the chordate neural tube. Furthermore, recent studies indicate a role of this structure as a proprioceptive organ, providing the necessary muscle tonicity to support a straight body axis in the embryo. In our view, this and other evidence can provide insights on the role of RF in the evolution of chordate's tail-powered swimming behavior, perhaps the key behavioral characteristic of this phylum. Here we will provide an overview of RF, its comparative structure and its diverse functions, and we will address comparative, clinical, and some recent experimental findings to suggest that this structure was associated with the definition of the body axis and swimming behavior in the early chordates.

\section{CHARACTERIZATION OF REISSNER'S FIBER (RF)}

As said, RF is an insoluble proteinaceous filament that floats in the CSF inside the chordate NCa. It is secreted by specialized ependymal cells in the mesencephalic-diencephalic (M-D) junction and extends toward the caudal end of the neural tube, where it decomposes and its material enters the meningeal CSF and the bloodstream (Rodríguez et al., 1992, 1998). Since it was first described by Reissner (1860) in the lamprey, it has remained an enigmatic component of the chordate neural tube, to which many functions have been ascribed.

\section{Composition and Comparative Structure}

Reissner's fiber is present in the $\mathrm{NCa}$ of most chordates, including cephalochordates, urochordates, and vertebrates excepting postnatal humans and a few other mammals. It consists of an agglomerate of elastic filaments, mainly composed of the glycoprotein SCO-spondin that contains high amounts of sialic acid, which enhances its adhesive properties (Olsson and Wingstrand, 1954; Olsson, 1972; Holmberg and Olsson, 1984; Rodríguez et al., 1992; Olsson et al., 1994; Gobron et al., 1999). SCO-spondin is a large extracellular matrix molecule containing a multidomain arrangement that includes von Willebrand factor D domains, SCO-spondin repeats, thrombospondin (TSR) domains, and LDL receptor repeats, all components associated with cell adhesion and axonal guidance (Gobron et al., 1999; Meiniel and Meiniel, 2007). There is strong molecular homology of the SCO-spondin gene across species, suggesting that this gene is ancestral to all chordates (Gobron et al., 1999, 2000; Meiniel et al., 2008). Nonetheless, SCO-spondin has lengthened significantly in vertebrates by the addition of repeated TSR domains, which is probably related to its increasingly complex role in promoting axonal growth and neuronal cell differentiation, among other functions (Meiniel et al., 2008). In fact, this protein's multidomain structure was probably created by domain-shuffling of different gene domains, possibly before the origin of chordates (Kawashima et al., 2009).

Some findings point to the existence of genes orthologous to SCO-spondin in echinoderms and hemichordates (both representing the sister group of chordates according to some authors; Figure 2) and possibly in all bilaterian animals, suggesting that RF-like material (but not a polymerized RF) was secreted by radial glia-like cells in the common ancestor of Bilateria (Gobron et al., 1999; Meiniel et al., 2008; Mashanov et al., 2009; Helm et al., 2017). Arendt et al. (2015) proposed that RF material derives from the secretion of mucociliary cells of ancestral metazoans (exemplified by present-day placozoans) that move food particles into the extracellular digestive cavity (Arendt et al., 2015).

\section{Sites of Production}

In late vertebrate development, $\mathrm{RF}$ is secreted by the subcommissural organ (SCO), a dorsal circumventricular organ located below the posterior commissure in the dorsal neural tube (the roof plate) at the M-D junction (dorsal prosomer P1; Nieuwenhuys, 1988; Meiniel et al., 1996; Grondona et al., 2012; Puelles, 2018; Muñoz et al., 2019; Diaz and Puelles, 2020; Figure 3). The SCO has a complex histological structure containing specialized, elongated ependymal cells with a basal process contacting the perivascular space that receives synaptic connections and an apical process that reaches the central canal and secretes RF, among other components (Rodríguez et al., 1992). SCO secretion includes RF and other components like the thyroid hormone transporter transthyretrin, basic fibroblast growth factor and other glycoproteins, some of which are soluble and reach the bloodstream via the ependymal cell's basal end, or the CSF via the cell's apical extreme. RF formation in the SCO's apical surface involves the "packaging" of the secreted proteins by disulfide bonds to form an insoluble thread that grows along the NCa (Rodríguez et al., 1992; Vio et al., 2008; Kiecker, 2018). However, SCO is not the only site of RF production during embryogenesis. In the early embryos of several vertebrates from fish to mammals, RF material is first secreted by the (ventral) floor plate cells, together with similar proteins like F-spondin. Later, RF material becomes secreted by a specialized flexural organ (FO) of the ventral M-D cephalic flexure (prosomers P1 and/or P2) and assembled into RF. Only in later stages, the SCO starts contributing to RF, together with the FO until the latter ceases its function, and only the SCO produces RF in the adult (Oksche, 1969; Lichtenfeld et al., 1999; Meiniel et al., 2008).

This developmental sequence seems to match the phylogenetic history of RF production. In cephalochordates, RF is secreted by the infundibular organ (IO), located in the diencephalic floor plate (Olsson and Wingstrand, 1954; Olsson, 1972; Olsson et al., 1994; Wicht and Lacalli, 2005; Figure 3). Based on possessing highly similar secretory mechanisms and topographic position (both are located in the site corresponding to the cephalic flexure, likely in prosomer $\mathrm{P} 1 / \mathrm{P} 2$ ), the embryonic FO has been considered to be homologous to the cephalochordate IO (Olsson and Wingstrand, 1954; Oksche, 1969; Olsson, 1972; Rodríguez et al., 1992; Olsson et al., 1994; Wicht and Lacalli, 2005). That is, both structures may derive from a structure present in the last common ancestor of vertebrates and cephalochordates.

Notably, larval urochordates also produce a RF-like structure that in some species is secreted by a specialized fibrinogen cell (FC) in the tail neural cord, which has been compared to the cephalochordate IO by virtue of secreting the same material 


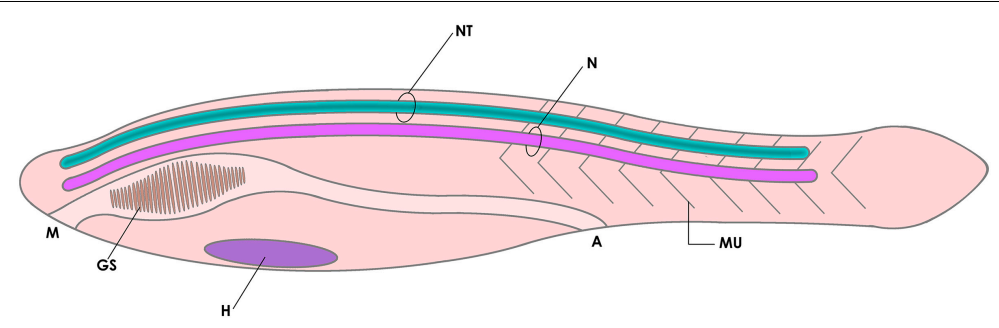

FIGURE 1 | Diagram of the basic elements of the chordate body plan, featuring a tadpole-like animal with a fibrous notochord (N) and a hollow neural tube (NT) in the dorsal side (cavitation is shown in dark green), a muscular tail (MU) for swimming, and gill slits (GS, a character shared with other deuterostomes). A, anus; $\mathrm{H}$, heart; M, mouth.

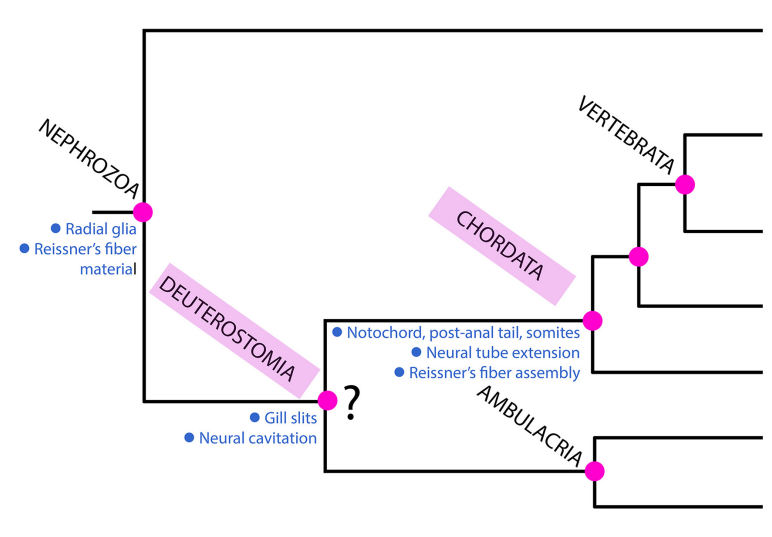

PROTOSTOMIA

GNATHOSTOMATA

AGNATHA

UROCHORDATA

CEPHALOCHORDATA

ECHINODERMATA

HEMICHORDATA

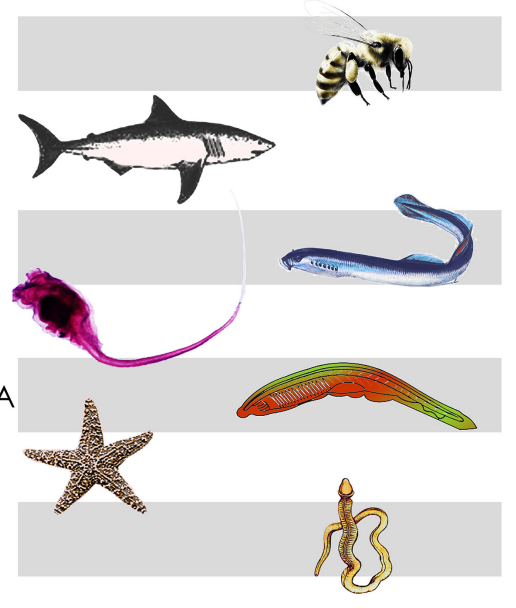

FIGURE 2 | Phylogeny of deuterostomes, indicating the points of origin of the characters discussed in this article. Most phylogenetic analyses place Deuterostomia as a monophyletic group (as depicted here), with Chordata and ambulacria as sister groups. However, some recent findings using large scale genetic databases claim that there is no evidence for Deuterostomia as a monophyletic group (Kapli et al., 2021). Hence the interrogation mark shown at this node. The main conclusions of this article are consistent with both views.

(Holmberg and Olsson, 1984). Phylogenetic analyses indicate that urochordates are the sister group of vertebrates, while cephalochordates represent this phylum's earliest branch (Bourlat et al., 2006). If this view is correct, the Amphioxus' IO may be closer to the ancestral RF secreting organ than the urochordate FC, the latter being a derived structure associated with the sessile lifestyle of urochordates as adults.

All three organs (IO, FC, and SCO) are located at the M-D junction in the different species (as said, prosomer P1), either in the floor plate (IO, FC) or in the roof plate (SCO). In recent years, several genes have been found to control SCO development and RF production (as well as the development of other organs too), including Pax6, SOX3, L1-CAM, and apoptosis-related genes (Estivill-Torrús et al., 2001; Ramos et al., 2004; CarmonaCalero et al., 2009; Lee et al., 2012; Matsumoto et al., 2020; Yang et al., 2021). It is possible that the expression of genes involved in IO (or FO) differentiation in the floor plate of the $\mathrm{M}-\mathrm{D}$ junction became co-opted in the roof plate during the origin of vertebrates, for reasons yet unknown. If this is correct, these structures, IO/FO on the one hand and SCO on the other, might qualify as serial homologs of each other (serial homology is a term used for repeated body structures like limbs or hairs; Montiel and Aboitiz, 2018). In other words, in the origin of vertebrates the ancestral developmental program involved in ventral RF secretion became activated in a different region, in the dorsal aspect of the M-D junction. As mentioned, the reasons for this transition remain as another mystery.

\section{HYPOTHESES ABOUT RF'S FUNCTIONS}

Despite all the accumulated knowledge about RF, there is no clarity about its primary, fundamental function, or adaptive significance (Rodríguez et al., 1992; Meiniel et al., 2008; Bearce and Grimes, 2021). In association with ciliary beating from ependymal cells, RF has been related to the circulation and ionic homeostasis of the CSF, where its high sialic acid contents enable it to bind CSF substances and transport them along the neural canal as the fiber grows. Mainly, RF may be involved in the transport and regulation of CSF monoamines, especially adrenaline, which regulates SCO secretion. Likewise, the SCO has been proposed to participate in osmoregulation, sodium excretion, diuresis, and water intake, although these findings remain controversial (Rodríguez et al., 1992; Muñoz et al., 2019). 


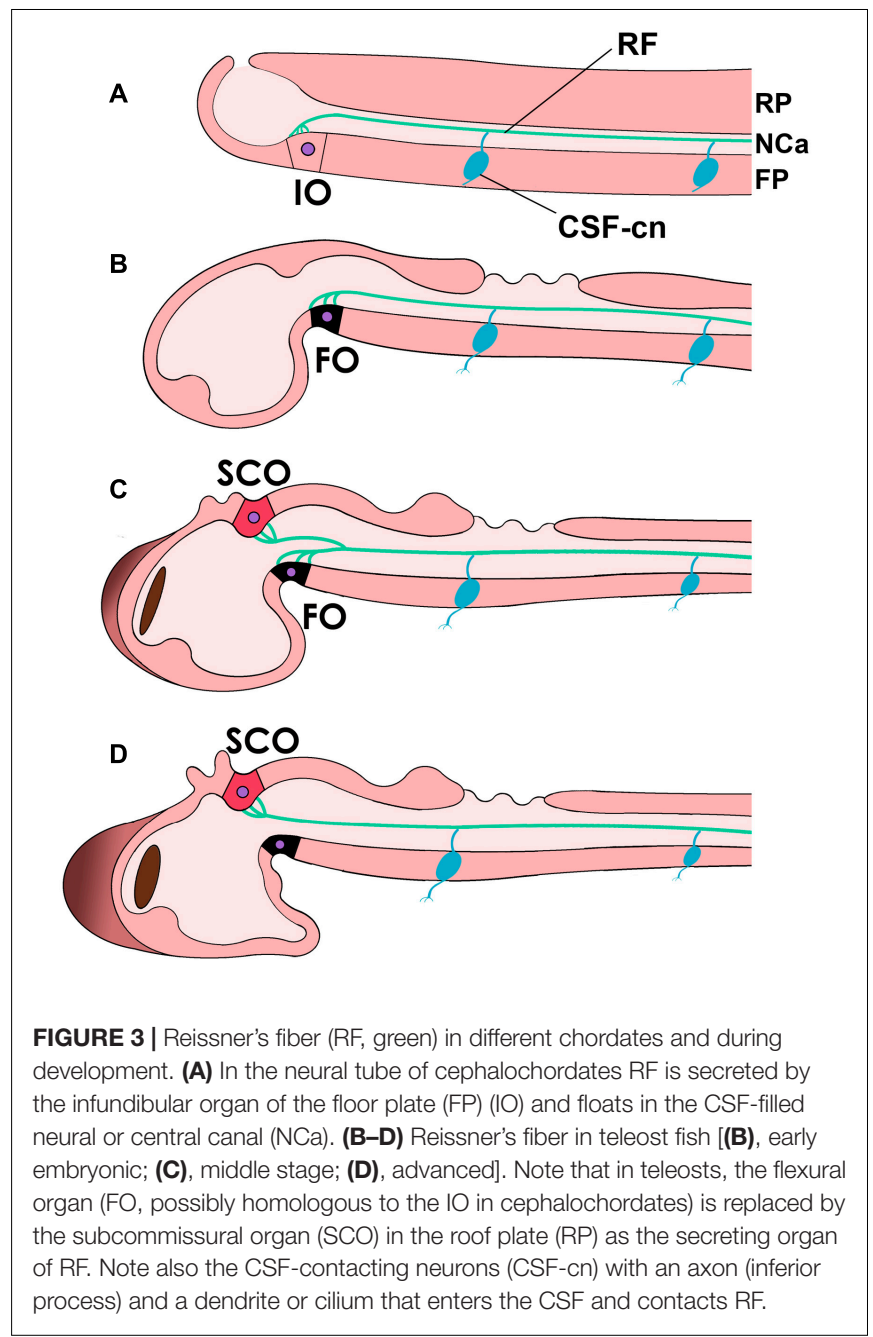

\section{Early Embryogenesis: Maintenance of the Neural Canal}

Hydrocephalus is a clinical condition where CSF accumulates in the cerebral ventricles due to neural tube defects that impair CSF circulation. Dysfunction of the SCO-RF complex has been associated with hydrocephalus in several species, including humans. Immunological damage to the SCO or absence of RF result in the collapse of the cerebral aqueduct (the $\mathrm{NCa}$ at the M-D junction) which blocks CSF flow, consequently increasing intraventricular pressure in the cerebral hemispheres (Overholser et al., 1954; Vio et al., 2000; Pérez-Fígares et al., 2001). The postnatal hydrocephalus hyh mouse develops absence of the $\mathrm{NCa}$ in the spinal cord and stenosis of the anterior mesencephalic aqueduct, as well as an impaired SCO and absence of RF (Irigoin et al., 1990). In this mutant, it was found that the ependyma's embryonic denudation starts in the ventral side and progresses dorsally during development, before the onset of postnatal hydrocephalus. The loss of floor plate cells and the lack of RF in this mutant may produce a distortion of the ependyma that collapses due to pressure produced by the brain parenchyma (Jiménez et al., 2001; Wagner et al., 2003).

\section{Roles in Later Neuronal Development and Function}

The SCO-RF complex not only has a role in early development but also interacts with the nervous system in diverse ways. During vertebrate development, the $\mathrm{SCO}$ and its secreted proteins have been associated with axonal guidance in the neural tube midline, a character shared by the roof and floor plates in the embryonic neural tube (Meiniel et al., 1996; Gobron et al., 2000; Grondona et al., 2012). RF has been also related to regeneration of the caudal neural tube in lower vertebrates (Meiniel et al., 1996; Alibardi, 2021), and soluble RF material secreted by the SCO has been proposed to contribute to adult neurogenesis in mammals (Guerra et al., 2015). In addition, the SCO is a highly innervated organ, receiving different inputs carrying monoamines, acetylcholine, neuropeptides, and GABA. Some findings suggest that serotonin and other monoamines may modulate SCO secretory activity, perhaps driven by signals generated from the neural tube itself (Rodríguez et al., 1992; Richter et al., 2004; El Hiba et al., 2020).

\section{CSF-Contacting Neurons}

Perhaps of more relevance to this article, the NCa walls contain abundant CSF-contacting neurons (CSF-cn) all along its length (Rodríguez et al., 1992; Bearce and Grimes, 2021). CSF-cn project dendrite-like extensions into the $\mathrm{NCa}$ and extend a large cilium and several stereocilia that contact RF. Although some of these neurons are apparently GABAergic, they are also positive for several other neurotransmitters, including monoamines, somatostatin (SST), and Urotensin II-related peptide (URP). URP neurons are innervated by SST+ axons, while SST+ neurons receive serotoninergic innervation (Rodríguez et al., 1992; Bearce and Grimes, 2021). These neurons extend axons to the lateroventral spinal cord and other regions and have been proposed to provide a feedback mechanism where CSF-cn may control the SCO activity (Rodríguez et al., 1992). CSF-cn, therefore, are in a position to sense a variety of chemical and mechanical stimuli from the CSF and RF, including bending of the RF and body axis and stimulating the dorsal musculature to correct these deviations (Böhm et al., 2016; Jalalvand et al., 2016). The latter suggests a role in locomotion and body position of CSF-cn and RF (Gobron et al., 1999, 2000), an issue that will be discussed below.

\section{Development of a Straight Body Axis}

Additionally, several studies suggest that RF alterations are involved in the pathogenesis of scoliosis. In this clinical condition, the vertebral spine curves sideways instead of maintaining a straight axis, affecting posture and worsening with age. Early in the last century, Nicholls (1913) and Kolmer (1921) proposed that RF could work as an axial proprioceptive organ, providing somatosensory control over the body and contributing to maintaining the body axis in the larval stage. Other studies performed last century had shown that SCO or RF disruption produced a distortion of the body axis in larval amphibians and fish (see Rodríguez et al., 1992). Additional evidence indicated that disruption of ependymal ciliary movements impairs CSF 
flow and produce curvature of the spine in zebrafish, suggesting a relation between ciliary movement and RF function (Brand et al., 1996; Kramer-Zucker et al., 2005; Bearce and Grimes, 2021). More recent studies performed in the zebrafish supported this possibility, demonstrating that RF is critical for maintaining a straight body axis and vertebral spine morphogenesis, as the absence of RF during development leads to scoliosis in the adult (Driever, 2018; Ringers and Jurisch-Yaksi, 2020). In a first study, Cantaut-Belarif et al. (2018) eliminated RF in mutants lacking SCO-spondin. On the first day after hatching, mutant larvae had a normally straight body axis (perhaps maintained by the nascent notochord), but after $30 \mathrm{~h}$, larvae displayed a trunk's distorted curvature. As mentioned, a similar phenotype has been observed in animals with ciliary movement defects in the ependymal cells lining the neural canal, which impairs CSF circulation (Bearce and Grimes, 2021). However, ciliogenesis and CSF circulation are normal in SCO-spondin mutants. On the other hand, in mutants with ciliary defects, RF does not form. Cantaut-Belarif et al. (2018) concluded that ciliary movement is needed to form RF and that RF, but not ciliary movement, is needed to maintain the body axis straight through larval development. In a subsequent study, hypomorphic SCO-spondin mutant larvae (expressing lower protein levels and forming a defective RF) produced a curved tail and scoliosis in the adult (Troutwine et al., 2020).

Another study demonstrated that RF stimulates mechanosensory cilia of CSF-cn in the spinal canal. When the axis is straight, RF floats in the neural canal, but when it curves comes into contact with mechanosensory neurons in the neural tube's inner wall that activate axial musculature, restoring the body's stiffness axis (Orts-Del'Immagine et al., 2020). Two further articles have shed additional insight into RF- CSF-cn mechanosensory transduction (Cantaut-Belarif et al., 2020; Lu et al., 2020). These studies showed that URP requires an intact RF to be expressed and is downregulated in SCO-spondin mutants, which results in impaired signaling to trunk muscles. Furthermore, treating mutants with epinephrine increased URP expression and rescued the phenotype, suggesting that this neurotransmitter mediates RF-CSF-cn signaling, perhaps via calcium transients in the spinal neurons. Furthermore, providing URP to the CSF resulted in a restoration of the larval and adult mutants' phenotype. Finally, SCO-spondin mutants also develop increased scoliosis-associated neuroinflammatory responses. Suppressing inflammation results in restoration of the wild-type phenotype (Rose et al., 2020). In discussing these findings, Ringers and Jurisch-Yaksi (2020) hypothesized that RF protects the spinal cord from inflammation and impairs normal maintenance of a straight body axis by inhibiting mechanosensory reflexes that maintain a stiff body posture.

\section{DISCUSSION: ROLE OF RF IN EARLY CHORDATE EVOLUTION}

As we have discussed above, despite much research being performed on RF there is no clarity yet about its primary role in neural development or in chordate evolution. Since RF and the SCO are required to prevent the collapse of the cerebral aqueduct of vertebrates, and a polymerized RF exists only in chordates, some authors have asked whether these components (more precisely, RF and the cephalochordate IO) might have contributed to the formation of the neural tube in chordate origins (Meiniel et al., 2008). However, a hollow nervous system may not be a chordate-specific character. The nerve cord of hemichordates (Figures 2,4) displays a localized cavitation that for many authors foreshadows the chordate neural tube (Kaul and Stach, 2010), although there are other opinions (Satoh, 2008). In any case, the origin of neurulation remains an unsolved problem. An early proposal prescribed that neurulation resulted from the invagination of two longitudinal ciliary bands present in the hypothetical ancestral dipleurula larva (Garstang, 1894; Holland, 2011). While being an appealing hypothesis, there is no evidence in its support yet. It is also possible that the secretion of nonpolymerized SCO-spondin proteins in the apical neuroectoderm contributed to the early invagination of the nerve cord in early deuterostomes or chordates (Meiniel et al., 2008), although again more evidence in this line is still needed.

Of note, the hemichordate neural tube is located in the collar region of the head, a region strongly positive for the genes Otx and Pax6, whose counterpart in chordates includes the M-D junction, according to gene expression mapping studies (Figure 4; Williams and Holland, 1996; Gobron et al., 1999; Holland and Short, 2008; Pani et al., 2012; Lowe et al., 2015). One possibility is that in chordate origins, the assembly of RF was associated with the development of an extended NCa running not only in anterior regions but also in caudal Otx-negative regions of the ancestral nerve cord; that is, into the body trunk and the post-anal tail. Embryonic elongation of the neural tube is a fundamental process shaping the chordate body plan (Lacalli, 2000). Yet, in lower vertebrates including ray finned fish and the lamprey, neural tube cavitation does not seem to occur at once but there is first a solid medullary cord (the neural keel) that cavitates at different levels along its length, becoming a continuous neural canal only later in development (Handrigan, 2003). Recalling the role of RF in preventing hydrocephalus, this structure may have participated in the production and maintenance of a continuous NCa along the longitudinal body axis in these species. In addition, it is of interest to recall that the posterior spinal cord innervating the chordate tail is produced by secondary neurulation, i.e., the formation of a secondary neural tube derived from tail bud mesenchyme, that later coalesces with the main neural tube (Handrigan, 2003; Beaster-Jones et al., 2008; Henrique et al., 2015). In cephalochordates, urochordates and vertebrates the tail's NCa contains a RF (Obermüller-Wilén and Olsson, 1974), and a RF is also present in the regenerating tail of lepidosaurians and other vertebrates (Meiniel et al., 1996; Alibardi, 2021). Therefore, it would be highly interesting to investigate whether RF contributed to the elongation and maintenance of the secondary neural canal in the tailbud of early chordates.

Beside its possible role in early chordate embryogenesis, RF may have been also crucial for the development of chordate swimming behavior, which eventually turned out to be the key for the success of vertebrates. In view of the recent evidence indicating a role of RF in the development of a straight axis, 


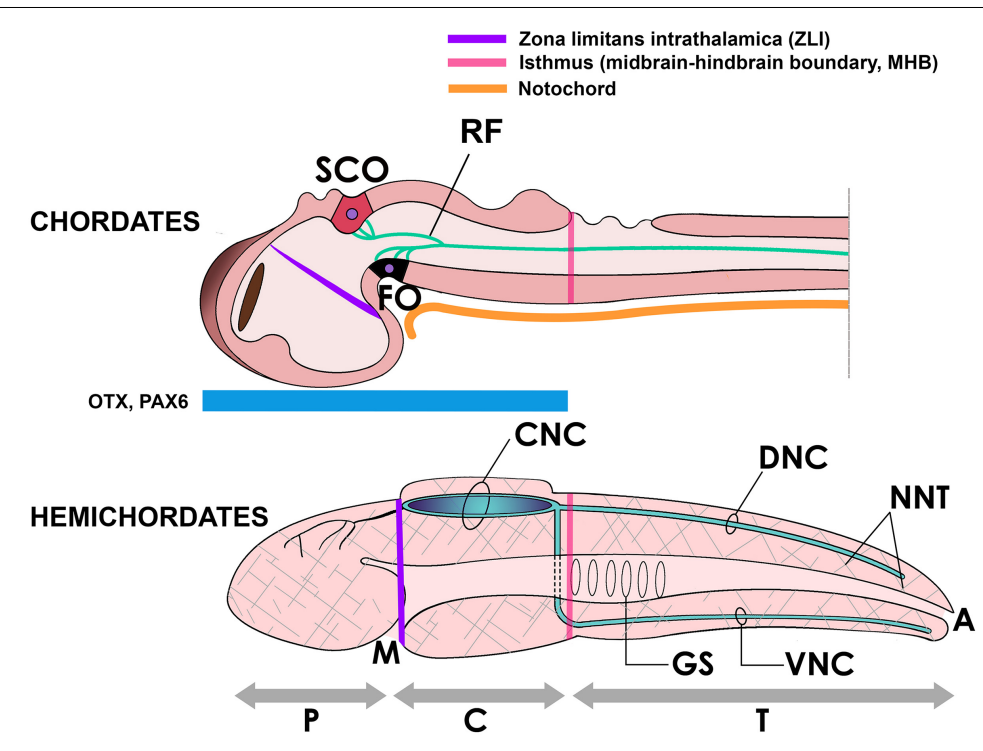

FIGURE 4 | Above, the neural tube of a chordate (embryonic fish) showing the subcommissural organ (SCO) and the flexural organ (FO), sites of origin of RF. These organs are located in the mesencephalic-diencephalic boundary, which is included in the embryonic region bound by the zona limitans intrathalamica (ZLI) anteriorly and the midbrain-hindbrain boundary (MHB) posteriorly. This region is strongly Otx-positive in early development and for this reason has been considered homologous to the location of the collar region (C) of the hemichordate body (below), displaying the same morphogenetic boundaries (ZLI and MHB homologs) and containing a hollow collar nerve cord (CNC) (Pani et al., 2012; Lowe et al., 2015). Beside the CNC, hemichordates display dorsal and ventral nerve cords (DNC,

VNC) in the body trunk (T) and a diffuse neural network (NNT, hatched areas) covering the body (Holland et al., 2015). A, anus; GS, gill slits; M, mouth; P, proboscis.

we tentatively suggest that in early chordates, the presence of a mechanically passive notochord might not have been sufficient to maintain the rigidness of the anteroposterior axis as the embryo grew in size. Stimulation of the notochord's contractile elements and of the dorsal musculature was required to maintain a straight body, which was provided by the RF/CSFcn proprioceptive circuit. In other words, RF in contact with CSF-cn (expressing URP or other neurotransmitters), may have provided a body position sensor that maintained the necessary tightness of the notochord and dorsal musculature in the growing larva, maximizing elastic energy during swimming strokes. Summarizing, elongation of the $\mathrm{NCa}$ into the trunk and tail regions, containing inside $\mathrm{RF}$ in contact with $\mathrm{CSF}-\mathrm{cn}$, may have been a key acquisition of early chordates that enabled not only the maintenance of a straight axis but may have also contributed to the neural control required for efficient swimming.

Notably, recent studies have shed light on another highly conserved event in early chordate development: a slight ventral bending of the embryonic tail during early development to fit the embryonic membranes' curvature. While this had been considered to result from external forces imposed to the growing embryo, it was found that actomyosin accumulates in the ventral side of the notochord, a condition that is required for proper bending of the tail (Lu et al., 2020). Whether RF and the CSF-cn participate in this process is also a matter for further research.

\section{FINAL COMMENTS}

This article has reviewed some old and recent findings regarding RF function from an evolutionary perspective. We hypothesize that the assembly of RF as a growing filament in the rudimentary $\mathrm{NCa}$ of chordate ancestors contributed to the extension of the neural tube into the tail region in concomitance with the differentiation of the notochord. This innovation also provided proprioceptive control to the body trunk and tail, facilitating the maintenance of a straight axis and the development of a contractile swimming tail. RF was first discovered some 160 years ago, and its function and strict conservatism across all chordates have remained an evolutionary mystery. The recent findings may provide some critical insight into its primary function during early chordate development and its maintenance in the phylum. Further research aimed at unveiling a possible participation of RF or its unpolymerized components in the process of neurulation, as well as in the role of this structure in the development of the body axis and swimming behavior may shed some further light into the origins of this intriguing neural tube component. Finally, understanding the role of RF in neural development may contribute to the treatment of spinal cord disorders, including hydrocephalus and scoliosis. In addition, considering a possible participation of RF in the lengthening of the neural canal and tail regeneration in lower vertebrates, further research could be directed to unveil the therapeutic involvement of this structure in spinal cord regeneration after injury or degenerative disease.

\section{AUTHOR CONTRIBUTIONS}

All authors listed have made a substantial, direct and intellectual contribution to the work, and approved it for publication. 


\section{REFERENCES}

Aboitiz, F., and Montiel, J. (2007). Origin and evolution of the vertebrate telencephalon, with special reference to the mammalian neocortex. Adv. Anat. Embryol. Cell Biol. 193, 1-112. doi: 10.1007/978-3-540-49761-5

Alibardi, L. (2021). Tail regeneration in Lepidosauria as an exception to the generalized lack of organ regeneration in amniotes. Exp. Zool. B. Mol. Dev. Evol. 336, 145-164. doi: 10.1002/jez.b.22901

Arendt, D., Benito-Gutierrez, E., Brunet, T., and Marlow, H. (2015). Gastric pouches and the mucociliary sole: setting the stage for nervous system evolution. Philos. Trans. R. Soc. Lond. B Biol. Sci. 370:20150286. doi: 10.1098/ rstb.2015.0286

Bearce, E. A., and Grimes, D. T. (2021). On being the right shape: roles for motile cilia and cerebrospinal fluid flow in body and spine morphology. Semin. Cell Dev. Biol. 110, 104-112. doi: 10.1016/j.semcdb.2020.07.005

Beaster-Jones, L., Kaltenbach, S. L., Koop, D., Yuan, S., Chastain, R., and Holland, L. Z. (2008). Expression of somite segmentation genes in amphioxus: a clock without a wavefront? Dev. Genes Evol. 218, 599-611. doi: 10.1007/s00427-008$0257-5$

Böhm, U. L., Prendergast, A., Djenoune, L., Nunes Figueiredo, S., Gomez, J., Stokes, C., et al. (2016). CSF-contacting neurons regulate locomotion by relaying mechanical stimuli to spinal circuits. Nat. Commun. 7:10866. doi: 10.1038/ ncomms 10866

Bourlat, S. J., Juliusdottir, T., Lowe, C. J., Freeman, R., Aronowicz, J., Kirschner, M., et al. (2006). Deuterostome phylogeny reveals monophyletic chordates and the new phylum Xenoturbellida. Nature 444, 85-88. doi: 10.1038/nature05241

Brand, M., Heisenberg, C. P., Warga, R. M., Pelegri, F., Karlstrom, R. O., Beuchle, D., et al. (1996). Mutations affecting development of the midline and general body shape during zebrafish embryogenesis. Development 123, 129-142.

Cantaut-Belarif, Y., Orts Del'Immagine, A., Penru, M., Pézeron, G., Wyart, C., and Bardet, P. L. (2020). Adrenergic activation modulates the signal from the Reissner fiber to cerebrospinal fluid-contacting neurons during development. Elife 9:e59469. doi: 10.7554/eLife.59469

Cantaut-Belarif, Y., Sternberg, J. R., Thouvenin, O., Wyart, C., and Bardet, P. L. (2018). The reissner fiber in the cerebrospinal fluid controls morphogenesis of the body axis. Curr. Biol. 28, 2479.e4-2486.e4.

Carmona-Calero, E. M., González-Marrero, I., González-Toledo, J. M., Castañeyra-Ruiz, A., De Paz-Carmona, H., Castañeyra-Ruiz, L., et al. (2009). Reissner's fibre proteins and p73 variations in the cerebrospinal fluid and subcommissural organ of hydrocephalic rat. Anat. Histol. Embryol. 38, 282-285. doi: 10.1111/j.1439-0264.2009.00939.x

Diaz, C., and Puelles, L. (2020). Developmental genes and malformations in the hypothalamus. Front. Neuroanat. 14:607111. doi: 10.3389/fnana.2020.607111

Driever, W. (2018). Developmental biology: reissner's fiber and straightening of the body axis. Curr. Biol. 28, R833-R835. doi: 10.1016/j.cub.2018.05.080

El Hiba, O., Draoui, A., and Gamrani, H. (2020). The neuroactive neurosteroid Dehydroepiandrosterone Sulfate (DHEAS) modulates the serotonergic system within the dorsal Raphe nucleus and the cerebrospinal fluid release of Reissner's fiber in rat. C. R. Biol. 343, 101-110. doi: 10.5802/crbiol.3

Estivill-Torrús, G., Vitalis, T., Fernández-Llebrez, P., and Price, D. J. (2001). The transcription factor Pax6 is required for development of the diencephalic dorsal midline secretory radial glia that form the subcommissural organ. Mech. Dev. 109, 215-224. doi: 10.1016/s0925-4773(01)00527-5

Garstang, W. (1894). Preliminary note on a new theory of the phylogeny of the Chordata. Zool. Anz. 17, 122-125.

Glover, J. C., and Fritzsch, B. (2009). "Brains of primitive chordates," in Encyclopedia of Neuroscience, 4th Edn, Vol. 6, ed. L. Squire (Oxford: Academic Press), 439-448.

Gobron, S., Creveaux, I., Meiniel, R., Didier, R., Dastugue, B., and Meiniel, A. (1999). SCO-spondin is evolutionarily conserved in the central nervous system of the chordate phylum. Neuroscience 88, 655-664. doi: 10.1016/s0306-4522(98) 00252-8

Gobron, S., Creveaux, I., Meiniel, R., Didier, R., Herbet, A., Bamdad, M., et al. (2000). Subcommissural organ/Reissner's fiber complex: characterization of SCO-spondin, a glycoprotein with potent activity on neurite outgrowth. Glia 32, 177-191. doi: 10.1002/1098-1136(200011)32:2<177::aid-glia70<3.0.co;2-v

Grondona, J. M., Hoyo-Becerra, C., Visser, R., Fernández-Llebrez, P., and LópezÁvalos, M. D. (2012). The subcommissural organ and the development of the posterior commissure. Int. Rev. Cell Mol. Biol. 296, 63-137. doi: 10.1016/B9780-12-394307-1.00002-3

Guerra, M. M., González, C., Caprile, T., Jara, M., Vío, K., Muñoz, R. I., et al. (2015). Understanding how the subcommissural organ and other periventricular secretory structures contribute via the cerebrospinal fluid to neurogenesis. Front. Cell Neurosci. 9:480. doi: 10.3389/fncel.2015.00480

Handrigan, G. R. (2003). Concordia discors: duality in the origin of the vertebrate tail. J. Anat. 202, 255-267. doi: 10.1046/j.1469-7580.2003.00163.x

Helm, C., Karl, A., Beckers, P., Kaul-Strehlow, S., Ulbricht, E., Kourtesis, I., et al. (2017). Early evolution of radial glial cells in Bilateria. Proc. Biol. Sci. 284:20170743. doi: 10.1098/rspb.2017.0743

Henrique, D., Abranches, E., Verrier, L., and Storey, K. G. (2015). Neuromesodermal progenitors and the making of the spinal cord. Development 142, 2864-2875. doi: 10.1242/dev.119768

Holland, L. Z., and Short, S. (2008). Gene duplication, co-option and recruitment during the origin of the vertebrate brain from the invertebrate chordate brain. Brain Behav. Evol. 72, 91-105. doi: 10.1159/000151470

Holland, N. D. (2011). Walter Garstang: a retrospective. Theory Biosci. 130, 247-258. doi: 10.1007/s12064-011-0130-3

Holland, N. D., Holland, L. Z., and Holland, P. W. (2015). Scenarios for the making of vertebrates. Nature 520, 450-455

Holmberg, K., and Olsson, R. (1984). The origin of Reissner's fibre in an appendicularian, Oikopleura dioica. Vidensk. Meddr Dansk Naturh. Foren. 145, 43-52.

Irigoin, C., Rodríguez, E. M., Heinrichs, M., Frese, K., Herzog, S., Oksche, A., et al. (1990). Immunocytochemical study of the subcommissural organ of rats with induced postnatal hydrocephalus. Exp. Brain Res. 82, 384-392. doi: 10.1007/ BF00231257

Jalalvand, E., Robertson, B., Wallén, P., and Grillner, S. (2016). Ciliated neurons lining the central canal sense both fluid movement and $\mathrm{pH}$ through ASIC3. Nat. Commun. 7:10002. doi: 10.1038/ncomms10002

Jiménez, A. J., Tomé, M., Páez, P., Wagner, C., Rodríguez, S., Fernández-Llebrez, P., et al. (2001). A programmed ependymal denudation precedes congenital hydrocephalus in the hyh mutant mouse. J. Neuropathol. Exp. Neurol. 60, 1105-1119. doi: 10.1093/jnen/60.11.1105

Kapli, P., Natsidis, P., Leite, D. J., Fursman, M., Jeffrie, N., Rahman, I. A., et al. (2021). Lack of support for Deuterostomia prompts reinterpretation of the first Bilateria. Sci. Adv. 7:eabe2741. doi: 10.1126/sciadv.abe2741

Kaul, S., and Stach, T. (2010). Ontogeny of the collar cord: neurulation in the hemichordate Saccoglossus kowalevskii. J. Morphol. 271, 1240-1259. doi: 10. 1002/jmor. 10868

Kawashima, T., Kawashima, S., Tanaka, C., Murai, M., Yoneda, M., Putnam, N. H., et al. (2009). Domain shuffling and the evolution of vertebrates. Genome Res. 19, 1393-1403. doi: 10.1101/gr.087072.108

Kiecker, C. (2018). The origins of the Circumventricular organs. J. Anat. 232, 540-553. doi: 10.1111/joa.12771

Kolmer, W. (1921). Das Sagittalorgan der wirbeltiere. Zeitschrift Anat. Entwicklungsgesch. 60, 652-717.

Kramer-Zucker, A. G., Olale, F., Haycraft, C. J., Yoder, B. K., Schier, A. F., and Drummond, I. A. (2005). Cilia-driven fluid flow in the zebrafish pronephros, brain and Kupffer's vesicle is required for normal organogenesis. Development 132, 1907-1921. doi: 10.1242/dev.01772

Lacalli, T. C. (2000). Cell morphology in amphioxus nerve cord may reflect the time course of cell differentiation. Int. J. Dev. Biol. 44, 903-906.

Lee, K., Tan, J., Morris, M. B., Rizzoti, K., Hughes, J., Cheah, P. S., et al. (2012). Congenital hydrocephalus and abnormal subcommissural organ development in Sox3 transgenic mice. PLoS One 7:e29041. doi: 10.1371/journal.pone. 0029041

Lichtenfeld, J., Viehweg, J., Schutzenmeister, J., and Naumann, W. W. (1999). Reissner's substance expressed as a transient pattern in vertebrate floor plate. Anat. Embryol. (Berl). 200, 161-174. doi: 10.1007/s004290050270

Lowe, C. J., Clarke, D. N., Medeiros, D. M., Rokhsar, D. S., and Gerhart, J. (2015). The deuterostome context of chordate origins. Nature 520, 456-465. doi: 10.1038/nature14434

Lu, H., Shagirova, A., Goggi, J. L., Yeo, H. L., and Roy, S. (2020). Reissner fibre-induced urotensin signalling from cerebrospinal fluid-contacting neurons prevents scoliosis of the vertebrate spine. Biol. Open 9:bio052027. doi: 10.1242/ bio.052027 
Mashanov, V. S., Zueva, O. R., Heinzeller, T., Aschauer, B., Naumann, W. W., Grondona, J. M., et al. (2009). The central nervous system of sea cucumbers (Echinodermata: holothuroidea) shows positive immunostaining for a chordate glial secretion. Front. Zool. 6:11. doi: 10.1186/1742-9994-6-11

Matsumoto, Y., Yamaguchi, Y., Hamachi, M., Nonomura, K., Muramatsu, Y., Yoshida, H., et al. (2020). Apoptosis is involved in maintaining the character of the midbrain and the diencephalon roof plate after neural tube closure. Dev. Biol. 2020, 101-109. doi: 10.1016/j.ydbio.2020.09.015

Meiniel, A., Meiniel, R., Didier, R., Creveaux, I., Gobron, S., Monnerie, H., et al. (1996). The subcommissural organ and Reissner's fiber complex. An enigma in the central nervous system? Prog. Histochem. Cytochem. 30, 1-66. doi: 10.1016/ s0079-6336(96)80015-5

Meiniel, O., and Meiniel, A. (2007). The complex multidomain organization of SCO-spondin protein is highly conserved in mammals. Brain Res. Rev. 53, 321-327. doi: 10.1016/j.brainresrev.2006.09.007

Meiniel, O., Meiniel, R., Lalloué, F., Didier, R., Jauberteau, M. O., Meiniel, A., et al. (2008). The lengthening of a giant protein: when, how, and why? J. Mol. Evol. 66, 1-10. doi: 10.1007/s00239-007-9055-3

Montiel, J. F., and Aboitiz, F. (2018). Homology in amniote brain evolution: the rise of molecular evidence. Brain Behav. Evol. 91, 59-64. doi: 10.1159/000489116

Muñoz, R. I., Kähne, T., Herrera, H., Rodríguez, S., Guerra, M. M., Vío, K., et al. (2019). The subcommissural organ and the Reissner fiber: old friends revisited. Cell Tissue Res. 375, 507-529. doi: 10.1007/s00441-018-2917-8

Nicholls, G. E. (1913). The structure and development of Reissner's fibre and subcommissural organ. Q. J. Microsc. Sci. 58(Part 1), 1-116.

Nieuwenhuys, R. (1988). "Amphioxus," in The Central Nervous System of Vertebrates, eds R. Nieuwenhuys, H. J. Ten Donkelaar, and C. Nicholson (Berlin: Springer), 365-396.

Obermüller-Wilén, H., and Olsson, R. (1974). The Reissner's fiber termination in some lower chordates. Acta Zool. 55, 71-79.

Oksche, A. (1969). The subcommissural organ. J. Neurovisc. Relat. 31(Suppl. 9), 111+. doi: 10.1007/978-3-662-25519-3_6

Olsson, R. (1972). Reissner's fiber in ascidian tadpole larvae. Acta Zool. Stockh. 53, $17-21$.

Olsson, R., and Wingstrand, K. G. (1954). Reissner's fiber and the infundibular organ in Amphioxus. Univ. Bergen Arbok (Publ. Biol. Stat.) 14, 1-14.

Olsson, R., Yulis, R., and Rodriguez, E. M. (1994). The infundibular organ of the lancelet (Branchiostoma lanceolatum Acrania): an immunocytochemical study. Cell Tiss. Res. 277, 107-114.

Orts-Del'Immagine, A., Cantaut-Belarif, Y., Thouvenin, O., Roussel, J., Baskaran, A., Langui, D., et al. (2020). Sensory neurons contacting the cerebrospinal fluid require the Reissner fiber to detect spinal curvature in vivo. Curr. Biol. 30, 827.e4-839.e4. doi: 10.1016/j.cub.2019.12.071

Overholser, M. D., Whitley, J. R., O’Dell, B. L., and Hogan, A. G. (1954). The ventricular system in hydrocephalic rat brains produced by a deficiency of vitamin B12 or folic acid in the maternal diet. Anat. Rec. 120, 917-933.

Pani, A. M., Mullarkey, E. E., Aronowicz, J., Assimacopoulos, S., Grove, E. A., and Lowe, C. J. (2012). Ancient deuterostome origins of vertebrate brain signalling centres. Nature 483, 289-294. doi: 10.1038/nature10838

Pérez-Fígares, J. M., Jimenez, A. J., and Rodríguez, E. M. (2001). Subcommissural organ, cerebrospinal fluid circulation, and hydrocephalus. Microsc. Res. Tech. 52, 591-607. doi: 10.1002/1097-0029(20010301)52:5<591::aid-jemt1043<3.0. co;2-7

Puelles, L. (2018). Developmental studies of avian brain organization. Int. J. Dev. Biol. 62, 207-224. doi: 10.1387/ijdb.170279LP

Ramos, C., Fernández-Llebrez, P., Bach, A., Robert, B., and Soriano, E. (2004). Msxl disruption leads to diencephalon defects and hydrocephalus. Dev. Dyn. 230, 446-460. doi: 10.1002/dvdy.20070

Reissner, E. (1860). Beiträge zur Kenntnis vom Bau des Rückenmarkes von Petromyzon fluviatilis L. Arch. Anat. Physiol. Wiss Med. (Leipzig). 77, 545-588.
Richter, H. G., Tomé, M. M., Yulis, C. R., Vío, K. J., Jiménez, A. J., Pérez-Fígares, J. M., et al. (2004). Transcription of SCO-spondin in the subcommissural organ: evidence for down-regulation mediated by serotonin. Brain Res. Mol. Brain Res. 129, 151-162. doi: 10.1016/j.molbrainres.2004.07.003

Ringers, C., and Jurisch-Yaksi, N. (2020). Development: how the reissner fiber keeps our back straight. Curr. Biol. 30, R705-R708. doi: 10.1016/j.cub.2020.04. 073

Rodríguez, E. M., Oksche, A., Hein, S., and Yulis, C. R. (1992). Cell biology of the subcommissural organ. Int. Rev. Cytol. 135, 39-121. doi: 10.1016/s00747696(08)62038-0

Rodríguez, E. M., Rodríguez, S., and Hein, S. (1998). The subcommissural organ. Microsc. Res. Tech. 41, 98-123. doi: 10.1002/(SICI)1097-0029(19980415)41: 2<98::AID-JEMT2<3.0.CO;2-M

Rose, C. D., Pompili, D., Henke, K., Van Gennip, J. L. M., Meyer-Miner, A., Rana, R., et al. (2020). SCO-Spondin defects and neuroinflammation are conserved mechanisms driving spinal deformity across genetic models of idiopathic scoliosis. Curr. Biol. 30, 2363.e6-2373.e6. doi: 10.1016/j.cub.2020.04.020

Sasai, N., Kadoya, M., and Ong Lee Chen, A. (2021). Neural induction: historical views and application to pluripotent stem cells. Dev. Growth Differ. 63, 26-37. doi: $10.1111 /$ dgd.12703

Satoh, N. (2008). An aboral-dorsalization hypothesis for chordate origin. Genesis 46, 614-622. doi: 10.1002/dvg.20416

Striedter, G. F., and Northcutt, R. G. (2020). Brains Through Time. A Natural History of Vertebrates. London: Oxford University Press.

Troutwine, B. R., Gontarz, P., Konjikusic, M. J., Minowa, R., Monstad-Rios, A., Sepich, D. S., et al. (2020). The reissner fiber is highly dynamic in vivo and controls morphogenesis of the spine. Curr. Biol. 30, 2353.e3-2362.e3. doi: 10. 1016/j.cub.2020.04.015

Vio, K., Rodríguez, S., Navarrete, E. H., Pérez-Fígares, J. M., Jiménez, A. J., and Rodríguez, E. M. (2000). Hydrocephalus induced by immunological blockage of the subcommissural organ-Reissner's fiber (RF) complex by maternal transfer of anti-RF antibodies. Exp. Brain Res. 135, 41-52. doi: 10.1007/s002210000474

Vio, K., Rodríguez, S., Yulis, C. R., Oliver, C., and Rodríguez, E. M. (2008). The subcommissural organ of the rat secretes Reissner's fiber glycoproteins and CSF-soluble proteins reaching the internal and external CSF compartments. Cerebrospinal Fluid Res. 5:3. doi: 10.1186/1743-8454-5-3

Wagner, C., Batiz, L. F., Rodríguez, S., Jiménez, A. J., Páez, P., Tomé, M., et al. (2003). Cellular mechanisms involved in the stenosis and obliteration of the cerebral aqueduct of hyh mutant mice developing congenital hydrocephalus. J. Neuropathol. Exp. Neurol. 62, 1019-1040. doi: 10.1093/jnen/62.10 .1019

Wicht, H., and Lacalli, T. H. (2005). The nervous system of amphioxus: structure, development and evolutionary significance. Can. J. Zool. 83, 122-150. doi: 10.1139/z04- 163

Williams, N. A., and Holland, P. W. H. (1996). Old head on young shoulders. Nature 383:490. doi: 10.1038/383490a0

Yang, S., Emelyanov, A., You, M. S., Sin, M., and Korzh, V. (2021). Camel regulates development of the brain ventricular system. Cell Tissue Res. 383, 835-852. doi: 10.1007/s00441-020-03270-1

Conflict of Interest: The authors declare that the research was conducted in the absence of any commercial or financial relationships that could be construed as a potential conflict of interest.

Copyright (c) 2021 Aboitiz and Montiel. This is an open-access article distributed under the terms of the Creative Commons Attribution License (CC BY). The use, distribution or reproduction in other forums is permitted, provided the original author(s) and the copyright owner(s) are credited and that the original publication in this journal is cited, in accordance with accepted academic practice. No use, distribution or reproduction is permitted which does not comply with these terms. 